\title{
2002 ACC/AHA Guideline Versus Clinician Judgment as Diagnostic Tests for Chest Pain
}

\author{
Stephen M. Hagberg, MD, Finbar Woitalla, DO, and Paul Crawford, MD
}

Purpose: Hospital admissions for chest pain are frequent and costly. The use of objective criteria to determine the need for hospitalization may save money. Here we compare the 2002 American College of Cardiology/American Heart Association (ACC/AHA) guidelines for the management of patients with unstable angina and non ST-segment elevation myocardial infarction to clinical judgment as diagnostic tests to predict which patients with chest pain will develop positive cardiac troponin-I.

Methods: Researchers conducted a retrospective chart review of patients admitted to a military community hospital for chest pain over a 2 -year period. The study determined sensitivity and specificity for both the ACC/AHA guidelines and consensus of clinical judgment to predict which subjects would develop positive cardiac troponin-I.

Results: Positive cardiac troponin-I was very low (7 of 386). Both the ACC/AHA guidelines and clinical judgment had sensitivities of $100 \%(95 \% \mathrm{CI}, 65-100)$ to predict positive cardiac troponin-I. The ACC/AHA guideline was 13\% specific (95\% CI, 12-13), with clinical judgment at $48 \%$ (95\% CI, 47-48). Classification as low risk had a high negative predictive value (ACC/AHA guideline, 1.00 [95\% CI, 0.951.00]; clinical judgment, 1.00 [95\% CI, 0.99-1.00]).

Conclusion: Patients categorized as low risk by either method could probably be discharged from the emergency department without developing positive troponin-I. (J Am Board Fam Med 2008;21: 101-107.)

People with chest pain constitute a large portion of annual admissions to hospitals in the United States, accounting for 722,000 (4\%) of admissions in 2002. At an estimated cost of $\$ 7500$ per hospital stay, this totals over $\$ 5.4$ billion annually. ${ }^{1,2}$ Many of these admissions are because of fear of litigation if the diagnosis of acute coronary syndrome (ACS) is missed. ${ }^{3-5}$ Some of this fear may be well-founded: up to $14 \%$ of those admitted in whom ACS is ruled out can have a cardiac event and $2 \%$ can die within 6 months. ${ }^{6}$ Of 2992 patients diagnosed with noncardiac chest pain, $2.8 \%$ had an adverse cardiac events within 30 days. $^{7}$

Although a low threshold for admitting patients with chest pain may avoid missing a life-threaten-

This article was externally peer reviewed.

Submitted 5 June 2007; revised 13 August 2007; accepted 16 August 2007.

From Misawa Air Base, Japan (SMH); Dyess Air Force

Base, Texas (FW); and Eglin Air Force Base, Florida (PC).

Funding: none.

Conflict of interest: none declared.

Disclaimer: The opinions and assertions contained herein are the private views of the authors and not to be construed as official, or as reflecting the views of the US Air Force Medical Service or the US Air Force at large.

Corresponding author: Paul Crawford, MD, 307 Boatner Rd, Ste 114, Eglin AFB, FL 32542 (E-mail: Drpaulcrawford@aol.com). ing diagnosis, it also results in both a substantial fiscal drain and a considerable number of false positive results, which lead to invasive testing and patient anxiety. To address these issues, several attempts have been made to study various risk factors in concert with examination and laboratory findings to develop algorithms that would clearly delineate low-risk from high-risk patients presenting to an emergency department with chest pain. ${ }^{8,9}$ No one study has found any combination that perfectly stratified all patients, but the majority of studies found similar key factors that aided in the prediction of patient outcome. The 2002 American College of Cardiology/American Heart Association (ACC/AHA) guidelines for the management of patients with unstable angina and non-ST segment elevation myocardial infarction include the following as predictors for ACS: sex; age; smoking/tobacco use; comorbidities of hypertension, hypercholesterolemia, or diabetes; pain characteristics such as duration, quality, radiation, circumstances of onset (ie, at rest or during exertion or stress), and reproducibility on examination; characteristic electrocardiogram findings; and elevated cardiac enzymes. ${ }^{10}$ Based on these findings, patients are generally stratified as low, intermediate, or high risk; 
however, the difficulty lies in the disposition of the low- and intermediate-risk patients because of the inherent ambiguity in several of the risk factors. The majority of studies that have delineated outcomes have been performed in larger tertiary care centers with entire wards dedicated to monitoring patients with chest pain or with catheterization teams available on site to perform emergent revascularization procedures. ${ }^{11}$

To evaluate whether mandatory application of the ACC/AHA guidelines in a community hospital setting could more accurately diagnose ACS when compared with clinician judgment without increasing patient risk, we performed a retrospective analysis of chest pain admissions to a community hospital. We used positive troponin-I as the "gold standard" against which we compared these diagnostic tests. ${ }^{12}$

\section{Methods}

The study used a retrospective, non-interventional chart review for diagnostic accuracy. All patients over the age of 18 admitted to Eglin AFB Hospital in Florida (has 45 beds and serves a population of $45,000)$ for chest pain from 1 June 2002 to 1 July 2004 were included in the study. The protocol excluded patients admitted during this period from the emergency department who had measurable troponin-I on initial laboratory evaluation and those for whom records were incomplete.

\section{Data Collection and Processing}

A pilot study of 30 charts allowed improvements in data collection. Researchers formalized definitions and recorded conventions during the pilot study. None of the pilot data collected was used in the final analysis. Power analysis of this data revealed the need to review 385 charts to detect a difference that could be generalized to a population of over 1 million.

Researchers reviewed charts in chronological order starting with 1 June 2002 and ending 30 June 2004. Researchers reviewed a total of 405 inpatient charts after charts with ICD-9 codes for chest pain and acute myocardial infarction were collected by records technicians. Those with specific ICD-9 codes for pericarditis, chest wall trauma, etc were not used. Researchers recorded data by hand on paper tracking sheets and collected demographic data (Table 1), including name, identification num-
Table 1. Characteristics of Study Patients and Prevalence of 2002 American College of Cardiology/ American Heart Association Guideline Criteria

\begin{tabular}{|c|c|}
\hline Finding & $\begin{array}{l}\text { Percent with finding } \\
\text { (no. of patients with } \\
\text { positive troponin-I } \\
\text { with finding) }\end{array}$ \\
\hline Age (years) & $57.4 \pm 13.6$ \\
\hline \multicolumn{2}{|l|}{ Sex } \\
\hline Male & 53 \\
\hline Female & 47 \\
\hline \multicolumn{2}{|l|}{ Subjective symptoms } \\
\hline Chest pain & $99(7)$ \\
\hline Shortness of breath & $5(0)$ \\
\hline Syncope/near syncope & $3(0)$ \\
\hline Arm pain & $2(0)$ \\
\hline Palpitations & $1(0)$ \\
\hline Nausea & $1(0)$ \\
\hline \multicolumn{2}{|l|}{ Risk level } \\
\hline \multicolumn{2}{|l|}{ ACC/AHA guideline } \\
\hline Low & 13 \\
\hline Intermediate & 2 \\
\hline High & 85 \\
\hline \multicolumn{2}{|l|}{ Clinical judgment } \\
\hline High & 47 \\
\hline Low & 53 \\
\hline History of CAD & $34(6)$ \\
\hline History of diabetes mellitus & $22(5)$ \\
\hline Positive troponin-I within 30 days & $2(7)$ \\
\hline Rest pain & $59(5)$ \\
\hline $\begin{array}{l}\text { Duration }>20 \text { minutes or increased } \\
\text { tempo of pain }\end{array}$ & $64(6)$ \\
\hline $\begin{array}{l}\text { New CP similar to previous anginal } \\
\text { episode }\end{array}$ & $15(2)$ \\
\hline $\begin{array}{l}\text { New S-T depression or bundle branch } \\
\text { block }\end{array}$ & $6(1)$ \\
\hline T-wave inversions with $\mathrm{CP}$ & $10(2)$ \\
\hline $\begin{array}{l}\text { New onset pulmonary edema } \\
\text { (rales on exam) }\end{array}$ & $3(0)$ \\
\hline New mitral regurgitant murmur & $3(1)$ \\
\hline $\begin{array}{l}\text { Abnormal vital signs } \\
\quad \text { (tachycardia, bradycardia, hypotension) }\end{array}$ & $12(2)$ \\
\hline Fixed Q-waves on ECG & $12(3)$ \\
\hline $\begin{array}{l}\mathrm{T} \text {-wave inversions in lateral leads with } \\
\text { large } \mathrm{R} \text {-waves }\end{array}$ & $21(4)$ \\
\hline Previous use of daily aspirin & $41(4)$ \\
\hline Normal ECG & $44(1)$ \\
\hline Reproducible chest pain & $1(0)$ \\
\hline Cocaine use & $0(0)$ \\
\hline
\end{tabular}

ACC/AHA, American College of Cardiology/American Heart Association; CAD, coronary artery disease; $\mathrm{CP}$, chest pain; ECG, electrocardiogram.

ber, date of admission, and date of discharge. These data included each of the criteria put forth in the 2002 ACC/AHA guideline for evaluation of chest 
pain (see Appendix 1). Investigators documented troponin-I results (3 consecutive values), additional cardiac testing performed with results, risk assessment using ACC/AHA criteria, risk assessment using researchers' clinical judgment, and the final outcome of the presence or absence of cardiac damage.

Clinical judgment was assigned based on a consensus of 2 experienced family physicians (range, 75-300 admissions for chest pain). After looking at documentation from the emergency department we assigned risk assessment based on our judgment, giving particular weight to symptoms of chest pain from exertion that was relieved by rest and EKG changes (ST segment depression or inverted $\mathrm{T}$ waves). Discordant assessments were discussed and the physicians reached a consensus. After assigning risk, the ACC/AHA guidelines and troponin-I levels were evaluated.

Risk category was assigned based on the ACC/ AHA guidelines. Patients with at least 2 high-risk features were categorized as "high risk." Researchers categorized patients as "intermediate risk" if they had one intermediate-risk factor with zero high-risk factors. "Low risk" patients had normal studies and benign chest pain. ${ }^{13}$ Records were excluded if initial troponin-I was positive or if patients were transferred for definitive care before admission. These patients were excluded because they had either a positive gold-standard test or had S-T elevation or severe depressions necessitating immediate intervention.

A codebook of definitions and recording conventions was created and strictly followed during the data collection phase. Each chart was reviewed and data were recorded in the datasheet by 2 independent reviewers who examined the entire inpatient chart. The principal investigator (S.H.) was one of the reviewers and securely kept the datasheets. An independent rater reviewed 20 randomly selected charts to ensure inter-rater variability; $99.4 \%$ of data points agreed $(\kappa=0.96)$. Investigators met twice each month to assess progress, assign risk scores, and identify difficulties with data collection. A research assistant entered the data into a spreadsheet (Microsoft Excel, Redmond, WA) with double password protection, and statistical calculations were made with this program.

\section{Outcome Measure and Primary Data Analysis}

The primary outcome measure was the presence of positive cardiac troponin-I (greater than $0.4 \mathrm{ng} /$
$\mathrm{mL}$ ) on any of the serial laboratory evaluations. This was considered the "gold standard" diagnostic test. Comparison was made between those subjects placed in one of 3 groups: (1) low-risk category versus the combination of intermediate- and highrisk categories per ACC/AHA guidelines; (2) lowrisk and intermediate-risk category versus high-risk categories per ACC/AHA guidelines; and (3) high or low risk based on clinical judgment. The sensitivity and specificity for each set of criteria in detecting patients with eventual positive cardiac troponin-I were calculated. Likelihood ratios and predictive values of each comparison group were also calculated with respect to future positive cardiac troponin-I values (within 30 days). Because the prevalence of positive troponin-I was low in our population $(1.8 \%)$, attention was given to likelihood ratios. Approval of the project with a Health Insurance Portability and Accountability Act waiver was obtained through the 96th Medical Group Institutional Review Board.

\section{Results}

There were significant differences in the numbers of patients stratified into low-, intermediate-, and high-risk groups when the use of ACC/AHA guidelines was compared with clinical judgment. Only 49 patients $(12.7 \%)$ were categorized as low risk by the ACC/AHA guidelines whereas 180 patients $(46.6 \%)$ were categorized as low risk by clinical judgment. Intermediate risk was assigned to only 9 patients $(2.3 \%)$ by the ACC/AHA guidelines. High risk encompassed 328 patients $(85 \%)$ by the ACC/ AHA guidelines but only $206(53.4 \%)$ by clinical judgment.

The outcome measure of positive troponin-I $(>0.4 \mathrm{ng} / \mathrm{mL})$ occurred infrequently; only 7 of 386 subjects $(1.8 \%)$ overall had this laboratory finding. The remainder (379 subjects; $98.2 \%$ ) had negative troponin-I. Of the subjects with positive troponin-I, the youngest subject was 65 years old.

\section{Sensitivity and Specificity Analyses}

Both the ACC/AHA guidelines high- and intermediate-risk groups and clinical judgment high-risk groups had sensitivities of 1.00 (95\% CI, 0.65-1.00) to detect patients who went on to develop positive cardiac troponin-I. Specificity calculations were much lower (Table 2). Patients classified as low risk by either method had negative likelihood ratios of 
Table 2. Utility to Detect Positive Troponin-I Values When Grouped by Risk

\begin{tabular}{lccc}
\hline Risk Score & $\begin{array}{c}\text { Positive Troponin-I } \\
(\mathrm{n}=7)\end{array}$ & $\begin{array}{c}\text { Negative Troponin-I }(<0.4) \\
(\mathrm{n}=379)\end{array}$ & $\begin{array}{c}\text { Total } \\
(\mathrm{n}=386)\end{array}$ \\
\hline
\end{tabular}

American College of Cardiology/American Heart Association guidelines' utility to detect positive troponin-I values when grouped by high versus intermediate and low risk

\begin{tabular}{llrr}
\hline High risk & 7 & 321 & 328 \\
Intermediate + low risk & 0 & 58 & 58 \\
Total & 7 & 379 & 386
\end{tabular}

American College of Cardiology/American Heart Association guidelines' utility to detect positive troponin-I values when grouped by high and intermediate versus low risk

\begin{tabular}{|c|c|c|c|}
\hline High + intermediate risk & 7 & 330 & 337 \\
\hline Low risk & 0 & 49 & 49 \\
\hline Total & 7 & 379 & 386 \\
\hline \multicolumn{4}{|c|}{ Clinical judgment's utility to detect positive troponin-I values when grouped by high versus low risk } \\
\hline High risk & 7 & 199 & 206 \\
\hline Low risk & 0 & 180 & 180 \\
\hline Total & 7 & 379 & 386 \\
\hline
\end{tabular}

zero (ACC/AHA guidelines, 0 [95\% CI, 0-2.81]; clinical judgment, 0 [95\% CI, 0-0.75]). The classification of patients as high risk by clinical judgment resulted in a positive likelihood ratio of 1.91 (95\% CI, 1.22-1.91) whereas ACC/AHA guideline classification of intermediate or high risk resulted in a positive likelihood ratio of $1.15(95 \% \mathrm{CI}$, 0.75-1.15) (Table 3).

\section{Limitations}

This study group had a very low incidence of positive troponin-I. This low incidence of ACS confounds calculations of sensitivity and specificity. A prospective study with randomization into 2 groups (clinician judgment versus ACC/AHA guidelines) would have reduced bias. In addition, experienced clinicians were used as the investigators; if junior staff or residents were used, this data may be less valid. In addition, this study was conducted at community hospital serving only Department of Defense beneficiaries. This population may not be generalizable to all patient populations.

Patients in whom the troponin-I was detectable at sub-threshold levels and later became undetectable proved difficult to categorize in our study, just as they would in a clinical setting. It is unclear if this level of troponin-I actually indicates myocardial damage or if it represents artifact. For the purposes of our study, we categorized these patients as not having had any myocardial damage so long as the troponin-I remained below the $0.4 \mathrm{ng} / \mathrm{mL}$ level. Although this is certainly a limitation of the study, it is also in keeping with the goal of the study to incorporate issues commonly found in a community hospital setting.

Table 3. Comparison of American College of Cardiology/American Heart Association Guideline and Clinical Judgment Using Troponin-I for Diagnosis of Patients Having Myocardial Infarction Within 30 Days

\begin{tabular}{|c|c|c|c|c|c|c|}
\hline Intervention & Sensitivity & Specificity & $\begin{array}{l}\text { Positive } \\
\text { Likelihood } \\
\text { Ratio }\end{array}$ & $\begin{array}{l}\text { Negative } \\
\text { Likelihood } \\
\text { Ratio }\end{array}$ & PPV & NPV \\
\hline $\begin{array}{l}2002 \text { ACC/AHA guidelines } \\
\text { (high vs. intermediate and low risk) }\end{array}$ & $1.00(0.65-1.00)$ & $0.15(0.15-0.15)$ & $1.18(0.77-1.18)$ & $0(0-2.37)$ & $0.02(0.01-0.02)$ & $1.0(0.96-1.00)$ \\
\hline $\begin{array}{l}2002 \text { ACC/AHA guidelines } \\
\text { (high and intermediate vs. low risk) }\end{array}$ & $1.00(0.65-1.00)$ & $0.13(0.12-0.13)$ & $1.15(0.75-1.15)$ & $0(0-2.81)$ & $0.02(0.01-0.02)$ & $1.00(0.95-1.00)$ \\
\hline Clinical judgment (high vs. low risk) & $1.00(0.65-1.00)$ & $0.48(0.47-0.48)$ & $1.91(1.22-1.91)$ & $0(0-0.75)$ & $0.03(0.02-0.03)$ & $1.00(0.97-1.00)$ \\
\hline
\end{tabular}

Values in parentheses are $95 \%$ CI.

$\mathrm{PPV}$, positive predictive value; NPV, negative predictive value. 


\section{Discussion}

In this retrospective study we determined that both ACC/AHA guidelines and clinical judgment could function as a safe and efficient method to rule out future positive cardiac troponin-I in patients evaluated in a community hospital emergency department. This finding is significant because other studies have found that formal criteria and clinician judgment can disagree in up to one-third of cases. ${ }^{14}$ In a rural practice network, diagnostic accuracy was high and not statistically different with the addition of the ACI time insensitive prediction instrument (TIPI) score versus clinician judgment $(86.8 \%$ ACI-TIPI off vs $89.0 \%$ ACI-TIPI on; $P=.15) .{ }^{15}$ Clinician judgment is perhaps an accurate predictor of whether a patient has ACS for settings in which volume is low and referral bias is lacking,.

Most research about the diagnostic accuracy of chest pain protocols has focused on tertiary hospitals with chest pain centers, and attempts have been made to find clinical predictor rules that rule out ACS. Prospective validation of the Thrombolysis in Myocardial Infarction risk score reveals that increasing scores indeed correlate with outcome. However, even in patients with a score of zero, $1.7 \%$ have an adverse cardiac outcome in 30 days. ${ }^{16}$ Alternatively, patients younger than 40 (mostly women and African-American) with no cardiac history, a normal electrocardiogram, and initial normal cardiac markers had a $0.14 \%$ (95\% CI, 0.1$0.2)$ risk of ACS. ${ }^{17}$ Although community hospitals account for large volumes of patients in aggregate, they do not have the individual volumes to justify dedicated chest pain centers. Without these specialized wards, the use of clinical predictor rules may be clumsy, especially when these rules and guidelines include the factors that physicians include when evaluating patients.

Because our study showed $100 \%$ sensitivity for both the ACC/AHA guidelines and clinical judgment in identifying those patients who go on to have positive troponin-I $(>0.4 \mathrm{ng} / \mathrm{mL})$ and relatively poor specificity, the utility of adding paperwork (often perceived as cumbersome by physicians) to the work-up of the patient with chest pain is probably low. In an urban emergency room setting, serial electrocardioram, 2-hour serum marker measurements, and selective nuclear stress testing in conjunction with physician judgment identifies and excludes myocardial infarction and 30-day ACS during the initial evaluation of patients with chest pain. ${ }^{18}$ In our study, the negative likelihood ratio for those who were assigned to the low-risk category was 0 for developing positive troponin-I, so patients in this category could possibly be discharged from the emergency department without admission to the hospital. This strategy could be especially beneficial to patients followed by family physicians who have strong patient relationships. In one study, patients referred for exercise testing and given a normal result had a perceived longer life expectancy and decreased anxiety and uncertainty 1 week after exercise testing as compared with before $(P<.01){ }^{19}$

Not only are there increased emotional and psychological costs associated with hospital admission for chest pain, but monetary costs are significant as well. A strategy of overnight admission and enzyme and exercise testing has an incremental cost of $£ 120,369$ per quality adjusted life year in the United Kingdom. ${ }^{20}$ Avoiding these admissions would be better for patients and society.

The authors would like to thank James Whitworth for his support with reviewing the manuscript and designing the study, and Diane Dodendorf for her assistance in coding data.

\section{References}

1. Pozen MW, D'Agostino RB, Selker HP, et al. A predictive instrument to improve coronary-care unit admission practices in acute ischemic heart disease: a prospective multicenter clinical trial. N Engl J Med 1984;310:1273-8.

2. Goldman L, Cook EF, Brand DA, et al. A computer protocol to predict myocardial infarction in emergency department patients with chest pain. N Engl J Med 1988;318:797-803.

3. Pope JH, Aufderheide TP, Ruthazer R, et al. Missed diagnoses of acute cardiac ischemia in the emergency department. N Engl J Med 2000;342:1163-70.

4. Lee TH, Rouan GW, Weisberg MC, et al. Clinical characteristics and natural history of patients with acute myocardial infarction sent home from the emergency room. Am J Cardiol. 1987;60:219-24.

5. Rusnak RA, Stair TO, Hansen K, Fastow JS. Litigation against the emergency physician: Common features in cases of missed myocardial infarction. Ann Emerg Med. 1989;18:1029-34.

6. Manini AF, Gisondi MA, van der Vlugt TM, Schreiber DH. Adverse cardiac events in emergency department patients with chest pain six months after a negative inpatient evaluation for acute coronary syndrome. Acad Emer Med 2002;9:896-902.

7. Miller CD, Lindsell CJ, Khandelwal S, et al. Is the 
initial diagnostic impression of "noncardiac chest pain" adequate to exclude cardiac disease? Ann Emerg Med 2004;44:565-74.

8. Goldman L, Cook EF, Johnson PA, et al. Prediction of the need for intensive care in patients who come to emergency departments with acute chest pain. N Engl J Med 1996;334:1498-504.

9. Selker HP, Beshansky JR, Griffith JL, et al. Use of the acute cardiac ischemic time-insensitive predictive instrument (ACI-TIPI) to assist with triage of patients with chest pain or other symptoms suggestive of acute cardiac ischemia: A multicenter, controlled clinical trial. Ann Intern Med 1998;129:845-55.

10. Braunwald E, Antman EM, Beasley JW, et al. ACC/ AHA guidelines for the management of patients with unstable angina and non-ST-segment elevation myocardial infarction. J Am Coll Cardiol 2002;40: 1366-74.

11. Mitchell AM, Garvey JL, Chandra A, et al. Prospective multicenter study of quantitative pretest probability assessment to exclude acute coronary syndrome for patients evaluated in emergency department chest pain units. Ann Emerg Med 2006; 47:447.

12. Collinson PO, Gaze DC. Biomarkers of cardiovascular damage. Med Princ Pract 2007;16:247-61.

13. Braunwald E. Application of current guidelines to the management of unstable angina and non-STelevation myocardial infarction. Circulation 2003; 108(suppl 3):S28-37.
14. Nagurney JT, Brown DFM, Chae C, et al. Disagreement between formal and medical record criteria for the diagnosis of acute coronary syndrome. Acad Emer Med 2005;12:446-52.

15. Westfall JM, Van Vorst RF, McGloin J, Selker HP. Triage and diagnosis of chest pain in rural hospitals: implementation of the ACI-TIPI in the High Plains Research Network. Ann. Fam Med 2006;4:153-8.

16. Chase M, Robey JL, Zogby KE, Sease KL, Shofer FS, Hollander JE. Prospective validation of the Thrombolysis in Myocardial Infarction Risk Score in the emergency department chest pain population. Ann Emerg Med 2006;48:252-9.

17. Marsan RJ, Shaver KS, Sease KL, et al. Evaluation of a clinical decision rule for young adult patients with chest pain. Acad Emer Med 2005;12:26-32.

18. Fesmire FM, Hughes AD, Fody EP, et al. The Erlanger Chest Pain Evaluation Protocol: a one-year experience with serial 12-lead ECG monitoring, two-hour delta serum marker measurements, and selective nuclear stress testing to identify and exclude acute coronary syndromes. Ann Emerg Med 2002; 40:584-94.

19. Mushlin AI, Kern LM, Paris M, Lambert DR, Williams G. The value of diagnostic information to patients with chest pain suggestive of coronary artery disease. Med Decis Making 2005;25:149-57.

20. Goodacre S, Calvert N. Cost effectiveness of diagnostic strategies for patients with acute, undifferentiated chest pain. Emerg Med J 2003;20:429-33. 


\begin{tabular}{|c|c|c|}
\hline Chart Heading & Explanation & Definition/Rating \\
\hline Sex & Gender & $\begin{array}{l}\text { M, male } \\
\mathrm{F} \text {, female }\end{array}$ \\
\hline Age & Age in years & Whole numbers (1-100) \\
\hline DOA & Date of admission & $\mathrm{mm} / \mathrm{dd} / \mathrm{yy}$ \\
\hline DOD & Date of discharge & $\mathrm{mm} / \mathrm{dd} / \mathrm{yy}$ \\
\hline Sx & Symptoms & Descriptive verbage \\
\hline Rest pain & Chest pain at rest & $\begin{array}{l}0=\text { absent } \\
1=\text { present }\end{array}$ \\
\hline Dur/up tempo & Duration of chest pain & $\begin{array}{l}0=<20 \mathrm{~min} \\
1=>20 \mathrm{~min}\end{array}$ \\
\hline Hx CAD & History of coronary artery disease & $\begin{array}{l}0=\text { absent } \\
1=\text { present }\end{array}$ \\
\hline New $C P=$ angina & New chest pain same as prior anginal symptoms & $\begin{array}{l}0=\text { absent } \\
1=\text { present }\end{array}$ \\
\hline New STD/ BBB & New ST segment depression or bundle branch block & $\begin{array}{l}0=\text { absent } \\
1=\text { present }\end{array}$ \\
\hline TWI w/Sxs & T-wave inversions with symptoms of chest pain & $\begin{array}{l}0=\text { absent } \\
1=\text { present }\end{array}$ \\
\hline Rales & Pulmonary rales on exam & $\begin{array}{l}0=\text { absent } \\
1=\text { present }\end{array}$ \\
\hline New MR & New onset mitral regurgitation murmur & $\begin{array}{l}0=\text { absent } \\
1=\text { present }\end{array}$ \\
\hline Abnl VS & Abnormal vital signs (tachycardia, bradycardia, hypotension only) & $\begin{array}{l}0=\text { absent } \\
1=\text { present }\end{array}$ \\
\hline Prior ASA & Prior use of daily aspirin & $\begin{array}{l}0=\text { absent } \\
1=\text { present }\end{array}$ \\
\hline $\mathrm{DM}$ & History of diabetes mellitus & $\begin{array}{l}0=\text { absent } \\
1=\text { present }\end{array}$ \\
\hline Fixed QW & Fixed Q-wave on electrocardiogram & $\begin{array}{l}0=\text { absent } \\
1=\text { present }\end{array}$ \\
\hline Nml EKG & Normal electrocardiogram & $\begin{array}{l}0=\text { absent } \\
1=\text { present }\end{array}$ \\
\hline TWI/F $\lg \mathrm{R}$ & T-wave inversions or flattening in lateral leads with large $\mathrm{R}$-waves & $\begin{array}{l}0=\text { absent } \\
1=\text { present }\end{array}$ \\
\hline Repro CP & Reproducible chest pain & $\begin{array}{l}0=\text { absent } \\
1=\text { present }\end{array}$ \\
\hline Cocaine use & History of cocaine use & $\begin{array}{l}0=\text { absent } \\
1=\text { present }\end{array}$ \\
\hline TpI $1 / 2 / 3$ & Troponin I: 1st, 2nd, 3rd sets & $\begin{array}{l}0=\text { absent } \\
1=\text { present }\end{array}$ \\
\hline Add test & Additional test & $\begin{array}{l}0=\text { not done } \\
1=\text { negative evaluation } \\
2=\text { abnormality on evaluation } \\
3=\text { evidence that test was done } \\
\quad \text { but results not available }\end{array}$ \\
\hline Risk & Risk score & $\begin{array}{l}0=\text { low risk } \\
1=\text { moderate risk } \\
2=\text { high risk }\end{array}$ \\
\hline Outcome & Cardiac damage & $\begin{array}{l}0=\text { no cardiac damage } \\
1=\text { cardiac damage }\end{array}$ \\
\hline
\end{tabular}

